\title{
In vitro differentiation of mouse embryonic stem cells into functional hepatocytes by sodium butyrate, hepatocyte growth factor and dexamethasone under chemically defined conditions
}

\author{
Yibo Yan, Bushuai Zhong, Weiwei Qi, Yang Song, Yongcong Wu, Yixuan Fan and Feng Wang* \\ Center of Embryo Engineering and Technology, College of Animal Science and Technology, Nanjing Agricultural \\ University, Nanjing 210095, China.
}

Accepted 25 May, 2011

\begin{abstract}
Studies have shown that embryonic stem (ES) cells can be successfully differentiated into liver cells, which offer the potential unlimited cell source for a variety of end-stage liver disease. In our study, in order to induce mouse ES cells to differentiate into hepatocyte-like cells under chemically defined conditions, ES cells were induced by sodium butyrate as inducer for 7 days in the first phase, followed by the combination of hepatocyte growth factor and dexamethasone as inducers for 12 days in the second phase based on an adherent culture system with a two-step induction. The results from the morphology, gene expression, protein molecular markers and cell function of ES-D3 cells derived hepatocyte-like cells demonstrated that $\mathrm{mES}$ cells can be differentiated efficiently in vitro to functional hepatocytes under chemically defined conditions, which might be useful as an in vitro system for hepatocyte transplantation therapy and toxicity screening in drug discovery.
\end{abstract}

Key words: Embryonic stem cells, hepatic-like cells, in vitro differentiation, sodium butyrate, hepatocyte growth factor, dexamethason.

\section{INTRODUCTION}

The liver is the major organ that provides multiple metabolic functions critical for the maintenance of homeostasis. One of the major causes of morbidity and mortality worldwide is liver failure or end-stage liver diseases for which orthotopic liver transplantation (OLT) is the accepted method of treatment. However, liver

*Corresponding author. E-mail: caeet@njau.edu.cn. Tel: +86025-84395381. Fax: +86-025-84395314.

Abbreviations: mES, Mouse embryonic stem cell; AFP, $\alpha-$ fetoprotein; AAT, $\alpha$-1-antitrypsin; HNF, hepatocyte nuclear factor; TAT, tyrosine aminotransferase; LIF, leukemia inhibitory factor; EBs, embryoid bodies; BAL, bioartificial liver; CK, cytokeratin; DAPI, 4,6-diamidino-2-phenylindole; Dex, dexamethasone; EGF, epidermal growth factor; FITC, fluorescein isothiocyanate; HGF, hepatocyte growth factor; ICG, indocyanine green; iPSC, induced pluripotent stem cell; MEF, mouse embryonic fibroblast; NEAA, non-essential amino acid; OLT, orthotopic liver transplantation; PAS, periodic acid Schiff. transplantation has several limitations, including high cost, side effects for the donor and requirement for immunosuppression, especially, the shortage of organ donors which limit the use of this therapeutic modality. During the last decade, hepatocyte transplantation therapy provides an alternative therapy strategy for liver failure or end-stage liver diseases (Tanaka et al., 2006). To enhance the potential for this approach, hepatocyte transplantation therapy requires a renewable cell source of functional hepatocytes in vitro. One of the most promising potential sources of functional hepatocytes is from embryonic stem (ES) cell or induced pluripotent stem cells (iPS).

ES cells and iPS cells are pluripotent cells and capable of giving rise to most tissues of the organism, including the germ line during development. ES cells or iPS cells have shown promise for use in regenerative medicine and regarded as a powerful resource for cell replacement therapy including its possible application for treating liver diseases. ES cell-derived or iPS cell-derived hepatocytes would be useful as a source of material for cell 


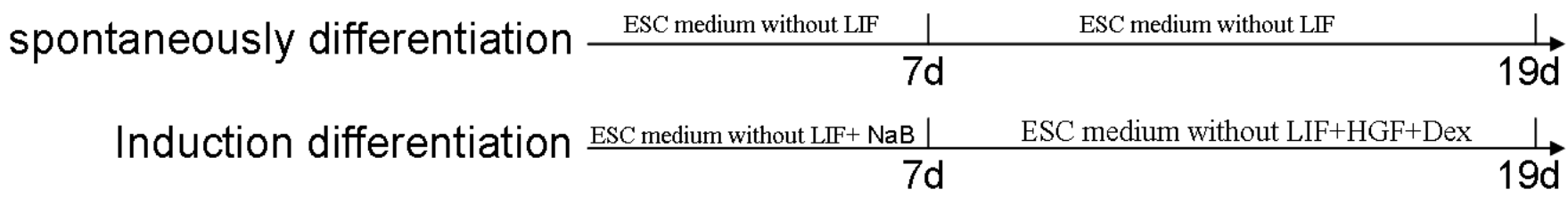

Figure 1. Schematic representation of the strategy for differentiation of ESC to hepatocytes.

transplantation, bioartificial liver (BAL) support devices, studies on hepatocyte biology and hepatitis viruses and drug testing. Previous studies indicated that ES cells could be differentiated into hepatocyte-like cells (Miyashita et al., 2002; Chinzei et al., 2002; Matsumoto et al., 2008; Mizumoto et al., 2008; Shiraki et al., 2008). Presently, iPS cell-derived hepatocytes have been reported (Si-Tayeb et al., 2010; Sullivan et al., 2010; Li et al., 2010; Gai et al., 2010; Liu et al., 2010). However, ES cells diffe-rentiation into hepatocyte is in infancy. We can differentiate ES cells into hepatocyte by simulating the mechanism of liver development, employing the related cytokines or compounds, genetic modification and coculture, which is complex technically, inefficient and costly, and most of the protocols currently used were devised to differentiate ES cells into hepatocyte by using embryoid bodies (EB) that may result in low yield or low purity of functional hepatocytes, therefore, the direct hepatic differentiation from an ES monolayer without using embryoid bodies is most promising (Teratani et al., 2005).

In this study, we established a novel procedure to differentiate ES cells into functional hepatocyte-like cells employing sodium butyrate (NaB) as inducer for 7 days in the first phase, followed by the combination of hepatocyte growth factor (HGF) and dexamethasone (Dex) as inducer for 12 days in the second phase using an adherent culture system with a two-step induction. The $\mathrm{NaB}$ is an epigenetic modulator and can direct the differentiation of ES cells into hepatic progenitors (Zhou et al., 2007; Ren et al., 2010). HGF and Dex play an important role in the maturation of hepatocytes (Ong et al., 2006). Our strategy is simple, efficient and relatively economical, based on two-step induction with $\mathrm{NaB}$ and cytokines under chemically defined conditions, and might provide a useful model and a potential source for liver development study and hepatocytes transplantation.

\section{MATERIALS AND METHODS}

\section{mES cells culture}

Undifferentiated ES-D3 cell was maintained on mitomycin C-treated mouse embryonic fibroblast (MEF) feeder cells in knockout Dulbecco's modified Eagle's medium (KD, Gibco), an optimized DMEM for ES cells, supplemented with $15 \%$ knockout serum replacement (KSR, Gibco), $1 \mathrm{mmol} / \mathrm{L}$ glutamine (Gibco), $0.1 \mathrm{mmol} / \mathrm{L}$ $\beta$-mercaptoethanol (Gibco), $100 \mathrm{mM} / \mathrm{L}$ nonessential amino acids (Sigma), $100 \mathrm{mg} / \mathrm{ml}$ penicillin and $100 \mathrm{mg} / \mathrm{ml}$ streptomycin (Sigma).
To help retain ES cells in an undifferentiated status, we added 1000 $\mathrm{U} / \mathrm{ml}$ recombinant mouse leukemia inhibitory factor (mLIF, Chemicon) to the culture medium.

MEF feeder cells were isolated from KM mice at embryo day 13.5 and cultured at $37^{\circ} \mathrm{C}$ and $5 \% \quad \mathrm{CO}_{2}$. At approximately $80 \%$ confluence, the feeder cells were incubated with $10 \mu \mathrm{g} / \mathrm{ml}$ mitomycin C (Sigma) for $2.5 \mathrm{~h}$ and washed six times with PBS (Gibco). Then the ES cells were seeded. Medium was changed every day until plates were confluent. Cells were dissociated using TrypLE Express (Gibco), and passage of the ES cells every 3 days by further replanting.

\section{Hepatic differentiation}

Differentiation of ES cells into hepatocytes was carried out as described in Figure 1. Before initiating differentiation, ES cells were trypsinized into single cell suspension and cultured onto $0.1 \%$ gelatin (Sigma) coated plates (Corning) without the feeder layer. Residual feeder cells could be removed by combination of differential adhesion and simple passage. To direct the differentiation of ES cells into hepatocytes in vitro (group 2, G2), medium was changed to ES differentiation medium (ES cells medium without $\mathrm{mLIF}$ ), supplemented with $3 \mathrm{mM}$ sodium butyrate (NaB, Sigma) for 7 days. Then, cells were further cultured in ES differentiation medium containing $20 \mathrm{ng} / \mathrm{ml}$ recombinant mouse hepatocyte growth factor (rMuHGF, R\&D Systerms) and $0.1 \mu \mathrm{M}$ dexamethasone (Dex, Sigma) for another 12 days. Differentiated cells were passaged upon achieving 90\% confluence. Spontaneously, differentiation group (group 1, G1) was used as a negative control that the cells of this group are treated by ES cells medium without $\mathrm{mLIF}$ during induction.

\section{Transmission electron microscopy observation}

Cell suspensions $\left(1 \times 10^{7}\right.$ cells $\left./ \mathrm{ml}\right)$ were centrifuged, the medium discarded, the cells fixed with $0.25 \%$ glutaraldehyde in PBS $(\mathrm{pH} 7.2)$ at $25^{\circ} \mathrm{C}$ for $2 \mathrm{~h}$, then post-fixed with $1 \% \mathrm{OsO}_{4}$, dehydrated in a graded series of ethanol solutions, infiltrated by propylene oxide, and finally embedded in epon. Ultrathin sections of the resulting sample were counterstained with $4 \%$ uranyl acetate, as well as lead citrate, and observed using $\mathrm{H}-7650$ Transmission Electron Microscope (Hitachi High-Technologies Co., Japan).

Hepatic specific gene expression analysis by real-time polymerase chain reaction (RT-PCR)

Total cellular RNA was extracted from $1.0 \times 10^{6}$ cells using PureLink $^{\mathrm{TM}}$ RNA Mini Kit (Invitrogen) according to the manufacturer's protocol. $2 \mu \mathrm{g}$ RNA sample was used to synthesize cDNA followed by PCR amplification using Thermocycler (TaKaRa Biotechnology Co Ltd). The PCR conditions were as follows: a first step of $5 \mathrm{~min}$ at $95^{\circ} \mathrm{C}$, a second step of 30 cycles for $30 \mathrm{~s}$ at $95^{\circ} \mathrm{C}$, a $30 \mathrm{~s}$ annealing step at 55 to $62^{\circ} \mathrm{C}$ and $30 \mathrm{~s}$ at $72^{\circ} \mathrm{C}$ and a final step 
of $7 \mathrm{~min}$ at $72^{\circ} \mathrm{C}$. Adult mouse liver was used as positive control. Primers used for amplification were: AFP(F:5'- CACTGC TGCAACTCTTCGTA-3') (R:5'-CTTTGGACCCTCTTCTGTGA-3'), 300bp; ALB(F:5'-GACAAGGAAAGCTGCCTGAC-3')(R:5'-TTCTGC AAAGTCAGCATTGG-3'),174bp;TTR(F:5' CTCACCACAGATGAGA AG-3') (R:5'-GGCTGAGTCTCTCAATTC-3'),225bp;AAT(F:5'-AAT GGAAGAAGCCATTCGAT-3') (R:5'-AAGACTGTAGCTGCTGCAG C-3'), $484 \mathrm{bp}$; PCR products then were subjected to electrophoresis in $2 \%$ agarose gels and stained with ethidium bromide.

\section{Immunostaining assay}

For immunostaining assay, cells were washed with PBS for 3 times respectively. Then the cells were fixed with pre-colded $4 \%$ paraformaldehyde (freshly prepared) for $15 \mathrm{~min}$ at room temperature. After aspirating the fixative, cells were washed three for 10 min each time with PBS. Then cells were incubated with TPBS (PBS containing $0.25 \%$ TritonX-100) for $10 \mathrm{~min}$, followed by washing for 3 times for 5 min each time with PBS. Non-specific binding was blocked with TPBS containing $5 \%$ bovine serum albumin (BSA) for $30 \mathrm{~min}$ at room temperature. The cells were then incubated with primary antibody (AFP, cell signaling, USA 1:100; ALB, Abcam, UK, 1:100; CK8 and 18, Bioworld, USA, 1:100) diluted with $1 \%$ BSA in TPBS containing $5 \%$ BSA at $4{ }^{\circ} \mathrm{C}$. The cells were then washed three times with TPBS and incubated with appropriate fluorophore-labeled secondary antibodies: TRITC-labeled Goat Anti-Mouse IgG (1:100, Bioworld), FITC-labeled Goat Anti-Rabbit $\lg$ (1:100, Bioworld) for $1 \mathrm{~h}$ at room temperature away from light. After washing with TPBS three times, nuclei were counterstained with $1 \mathrm{ug} / \mathrm{ml}$ 4',6-diamidino-2-phenylindole (DAPI, Roche) for $1 \mathrm{~min}$, then rinse with PBS. Images were captured using Zeiss fluorescence microscope.

\section{Periodic acid solution (PAS) reaction}

Cells were fixed with $4 \%$ phosphate buffered polyformalin solution for 3 5 min, and then washed three times with PBS. Fixed cells were exposed to $100 \mu \mathrm{l}$ of periodic acid solution per well for $10 \mathrm{~min}$. After rinsing with distilled water, $100 \mu \mathrm{l}$ of Schiff's reagent was added per well and cells were exposed for 10 20 min (incubation away from light). After removing the Schiff's reagent, $100 \mu \mathrm{l}$ of acid sulfite solution was added per well for $1 \mathrm{~min}$, then washing with distilled water to remove the reagent for $10 \mathrm{~min}$ and examined by Zeiss microscope.

\section{Indocyanine green uptake assay}

After washing the culture cells with PBS, Indocyanine Green (ICG, Sigma) solution was added to the plates at a final concentration of 1 $\mathrm{mg} / \mathrm{ml}$ and incubated at $37^{\circ} \mathrm{C}$ for $60 \mathrm{~min}$, then rinsed three times with PBS and the dishes were refilled with medium. ICG was completely eliminated from the cells $9 \mathrm{~h}$ later. The uptake and secretion of ICG is a specific function of hepatocytes.

\section{Measurement of differentiation ratio}

In this study, the hepatic differentiation ratio was determined by evaluating the percentages of ALB-positive cells in the differentiated cells. We randomly picked 6 wells from each group and 5 images from each well. ALB-positive cells and total cells counterstained with DAPI were counted using Zeiss fluorescence microscope. The values from each well were averaged to obtain a mean \pm S.D.

\section{Statistical analysis}

Data were expressed as mean \pm S.D. Statistical analysis were performed using the Statistical Package for the Social Sciences (SPSS) program. The significant differences between the groups were assessed by one-way analyses of variance (ANOVA) with Tukey test, and $P<0.05$ was considered as significant.

\section{RESULTS}

\section{Establishing mES cells feeder-free culture system}

Undifferentiated mESC-D3 cell was maintained on mitomycin C-treated feeder cells, which possess the normal characteristics of morphology and active proliferation (Figure 2A). We cultured mES-D3 cells in serumfree and feeder-free culture system by the combination of gelatin coating, KD and KSR. The method of combination of differential adhesion and simple passage could remove the feeder cells effectively (Figure 2B), which laid the foundation for the follow-up differentiation.

\section{Morphologic observation during differentiation}

Observation of light microscopy showed that the mESCD3 cell gradually differentiated into hepatocyte-like cells during differentiation (Figure 3). Examination with transmission electron microscopy revealed that the mES cells derived hepatocyte-like cells were similar to hepatocytes from a morphological viewpoint with abundant microvilli, numerous mitochondria, lipid droplets, rough endoplasmic reticulum, well-developed Golgi apparatus and occluding (tight) junctions normally present on the apical domain of hepatocytes (Figure 4). These results indicated that the mES cells derived hepatocyte-like cells possessed mature hepatocyte ultrastructures characteristics.

\section{Detection of hepatic specific genes by RT-PCR}

We detected the expression of some marker genes of ES-D3 cells derived hepatocyte-like cells by RT-PCR. The results showed that the ES-D3 cells derived hepatocyte-like cells expressed marker genes of AFP, ALB, TTR and AAT, the cells of spontaneous differentiation slightly expressed marker genes of AFP and ALB, but late markers TTR and AAT were not expressed (Figure 5). The results indicated that the ES-D3 cells derived hepatocyte-like cells possess the gene expression characteristics of hepatocyte and comprised of hepatocyte-like cells with different stages of maturity.

\section{Detection of hepatic-associated protein marker}

The results of immunofluorescence analysis showed that 

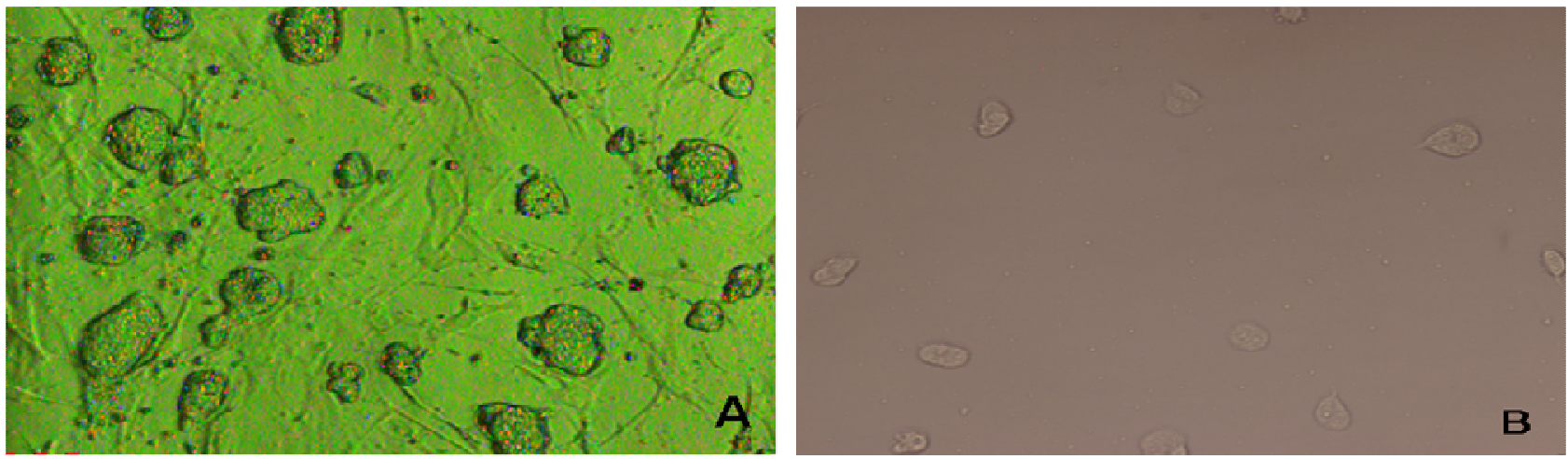

Figure 2. Culture of ES cell on feeder layers and gelatin (x100) (A) ES cell clone on feeder layers; (B) The 3rd passage of ES cell clone on gelatin after differential adhesion.

D3

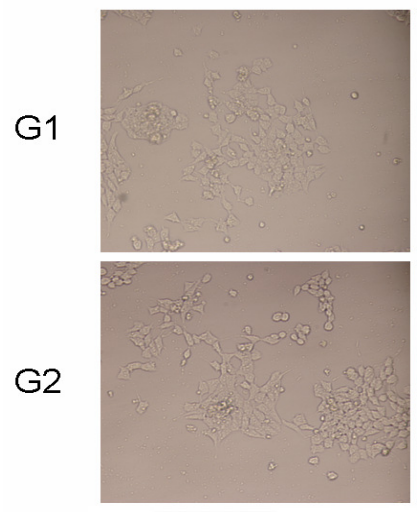

D7
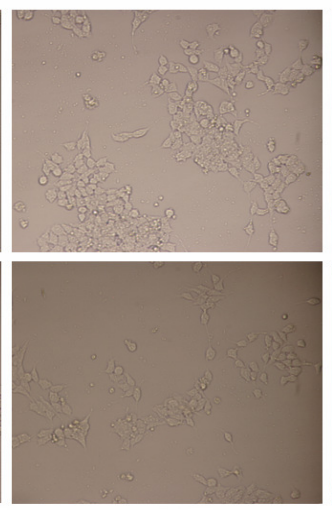

D12
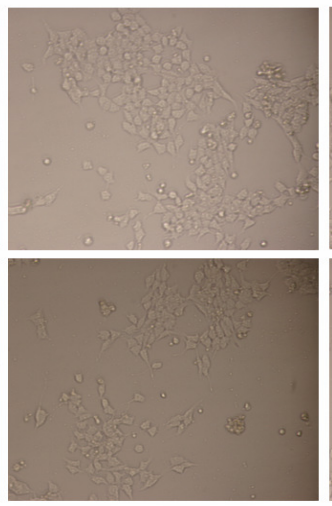

Figure 3. Morphology observation of ES cell differentiation (x100).
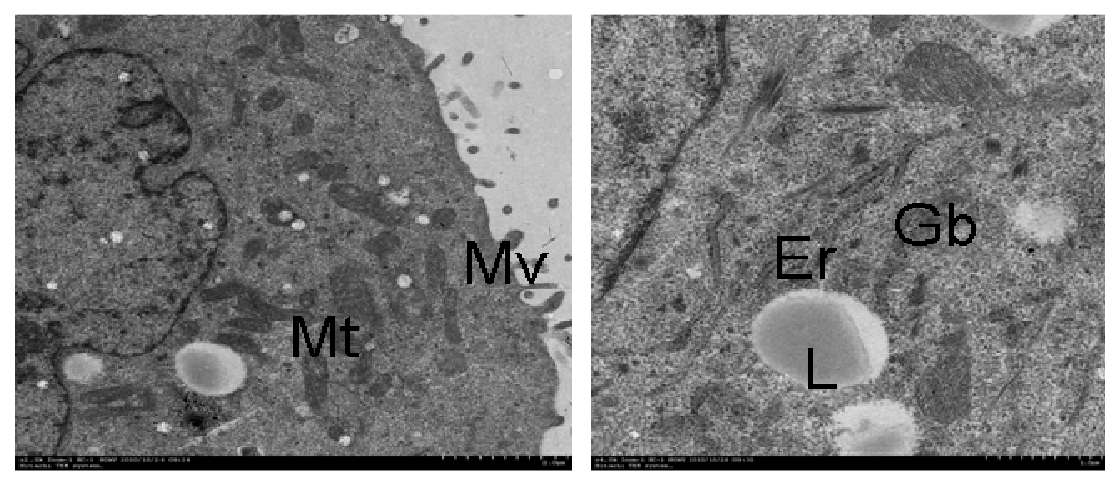

Figure 4. TEM images of induced cells $(\times 10000)$. Er: rough endoplasmic reticulum; Gb: Golgi apparatus; Mt: mitochondrion; Mv: microvillus; L: lipid granule.

the ES-D3 cells derived hepatocyte-like cells express hepatocyte-specific marker proteins ALB, AFP, CK8 and CK18, while in the spontaneous differentiation, group of some cells also expressed ALB and AFP, but CK8 and CK18 were not expressed (Figure 6).

\section{Cell function analysis}

PAS staining was performed to examine glycogensynthesis and storage, one of the characteristic functions of hepatocytes. After 19 days of differentiation, 


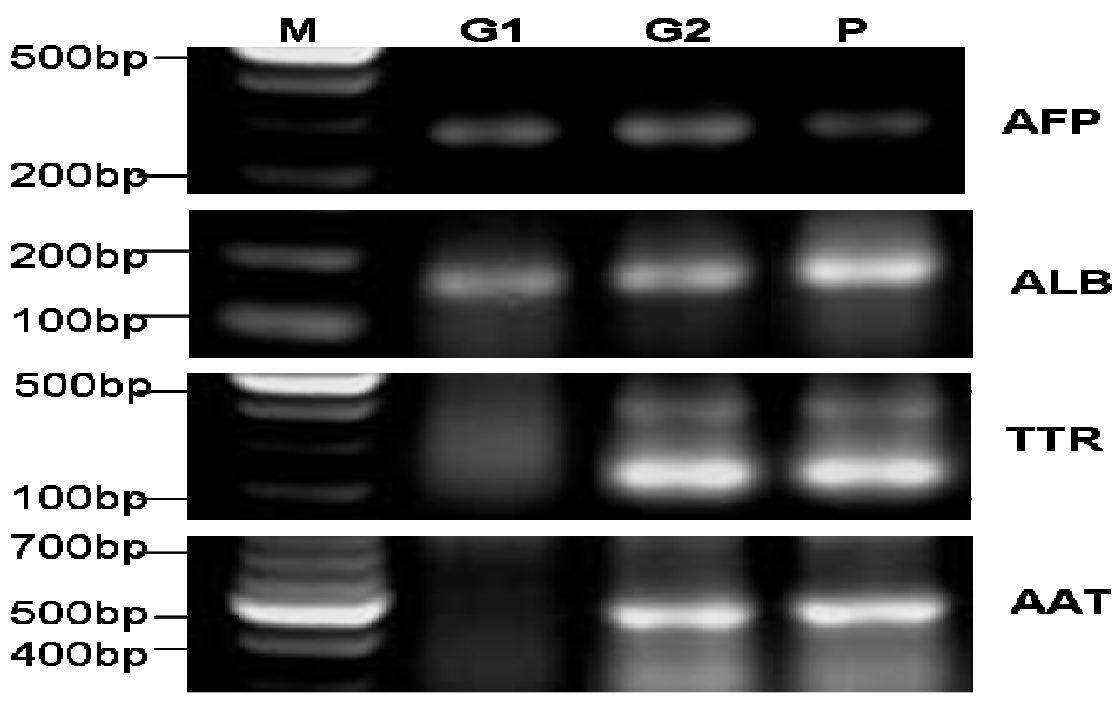

Figure 5. Detection of hepatocyte-specific markers by RT-PCR. M. Maker; P. Positive control

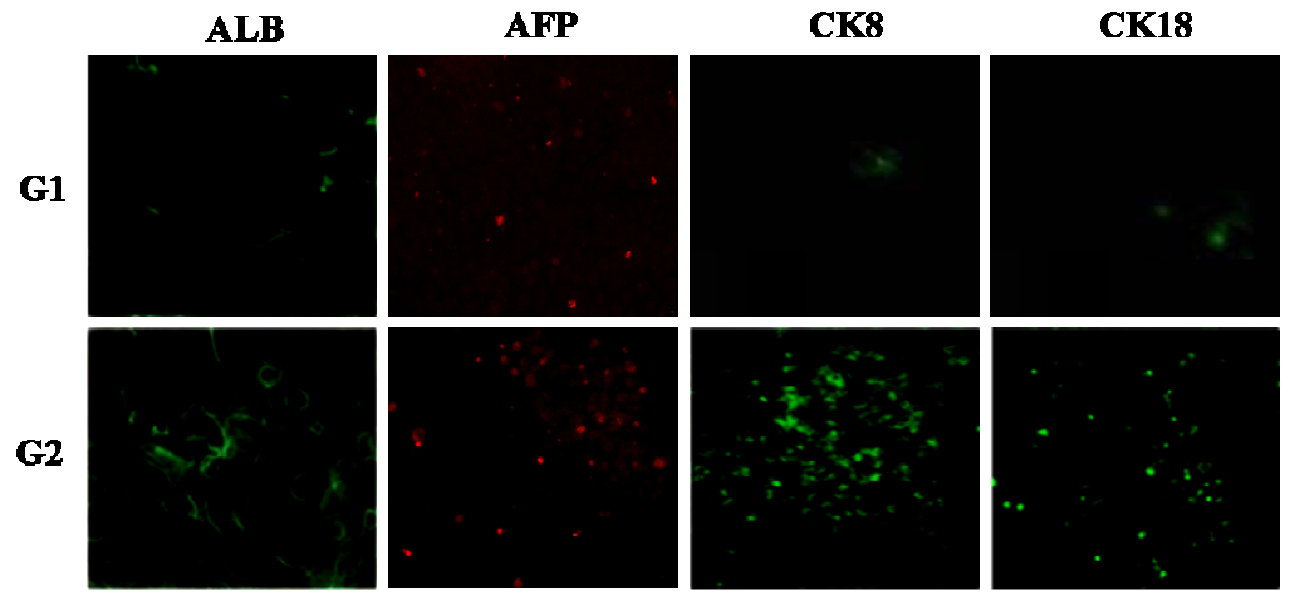

Figure 6. Immunofluorescence staining analysis of liver specific molecular markers (x 200).

a number of cells of $\mathrm{G} 2$ group were consistently positive for PAS stain, while many cells of $\mathrm{G} 1$ group were negative or slight staining (Figure 7). In addition, the ICG metabolism of cultured cells was also examined. Results showed that the ES-D3 cells derived hepatocyte-like cells of differentiation groups possess the metabolic function of ICG, while only a small number of cells in spontaneously differentiated group possess the metabolic function of ICG (Figure 8). These results suggested that the ES-D3Hep cells have hepatocyt specific cell function.

\section{Differentiation ratio comparison}

Differentiation rate of hepatocyte was determined by evaluating the percentages of ALB-positive cells in the differentiated cells. Approximately, $37.27 \%$ of the cells expressed the hepatic marker ALB by day 19 of culture in differentiation groups. Meanwhile, differentiation rate of spontaneous differentiation group is $8.25 \%$, the difference was significant $(P<0.05)$ (Figure 9$)$.

\section{DISCUSSION}

ES cells have been regarded as a new cell source for cell replacement therapy. Establishing an effective technology of differentiation is an important direction of ES cells research, which provided the desired cell source for the repair of tissue injury and disease. Recently, differentiation of hepatocytes from ES cells has been reported using either in vitro, in vivo differentiation protocols, or 

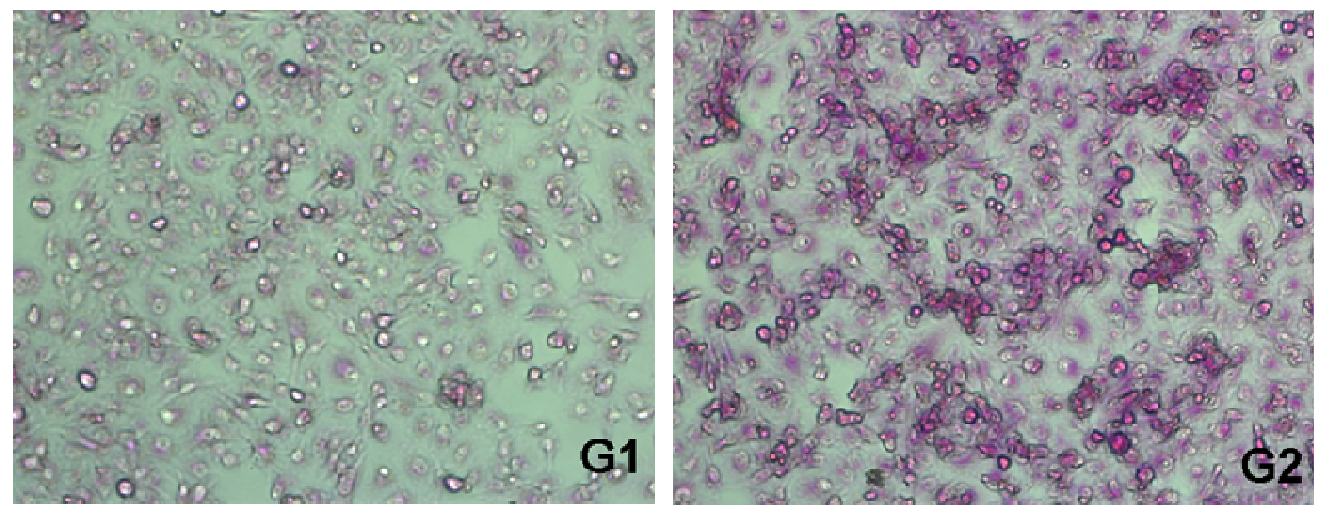

Figure 7. Periodic acid Schiff (PAS) staining $(\times 100)$. Glycogen storage ability of differentiation cells.

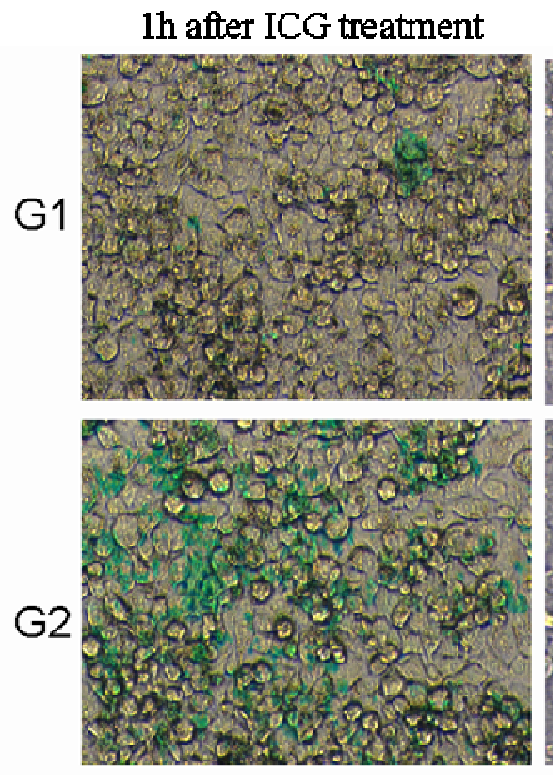

\section{9h after ICG treatment}
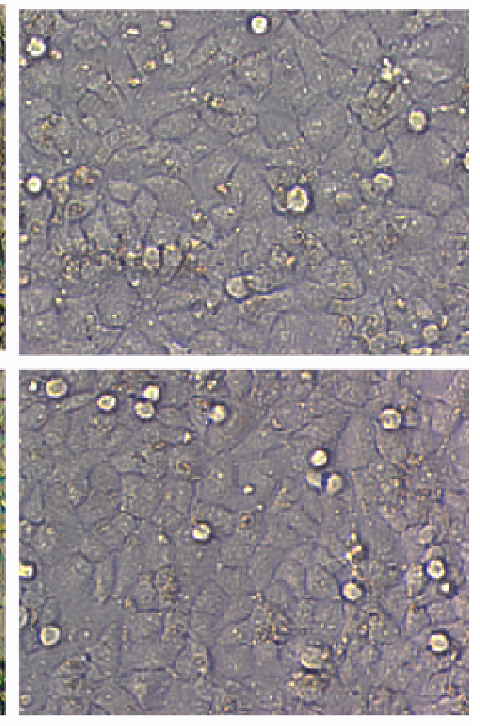

Figure 8. ICG uptake/excretion test (x200). Ability examination of differentiation cells to take up ICG (left column) and release it $9 \mathrm{~h}$ later (right column).

protocols combining both approaches because the liver plays a major role in metabolism and has multiple functions, including glycogen storage, decomposition of red blood cells, plasma protein synthesis, and detoxification. A number of studies have demonstrated the feasibility of differentiating ES cells into the hepatic lineage (Soto-Gutierrez et al., 2006; Gouon-Evans et al., 2006; Drobinskaya et al., 2008).

Although, hepatocytes derived from ES cells promise a potential for treating liver or liver-related diseases. Most of the protocols currently developed to induce the hepatic differentiation from ES cells were devised by using embryoid bodies. It is time-consuming and may result in low yield and purity of functional hepatocytes. A previous study has demonstrated that hepatocyte-like cells could be directly induced from human ES cells by using a combination of cytokines (Hay et al., 2007). However, the direct hepatic differentiation of ES cells still remains a challenge and needs to be further developed. Based on chemically defined serum-free culture system of the combination of KD and KSR, we used the method of combination of differential adhesion and simple passage to remove feeder cells, which laid the foundation for the follow-up differentiation.

Epigenetic modification is considered to be the main mechanism of cell differentiation involving in gene expression regulation and can be used as induction differentiation strategy. Histone acetylation is considered to be one of the most important epigenetic modification regulating gene expression, which is largely controlled by 


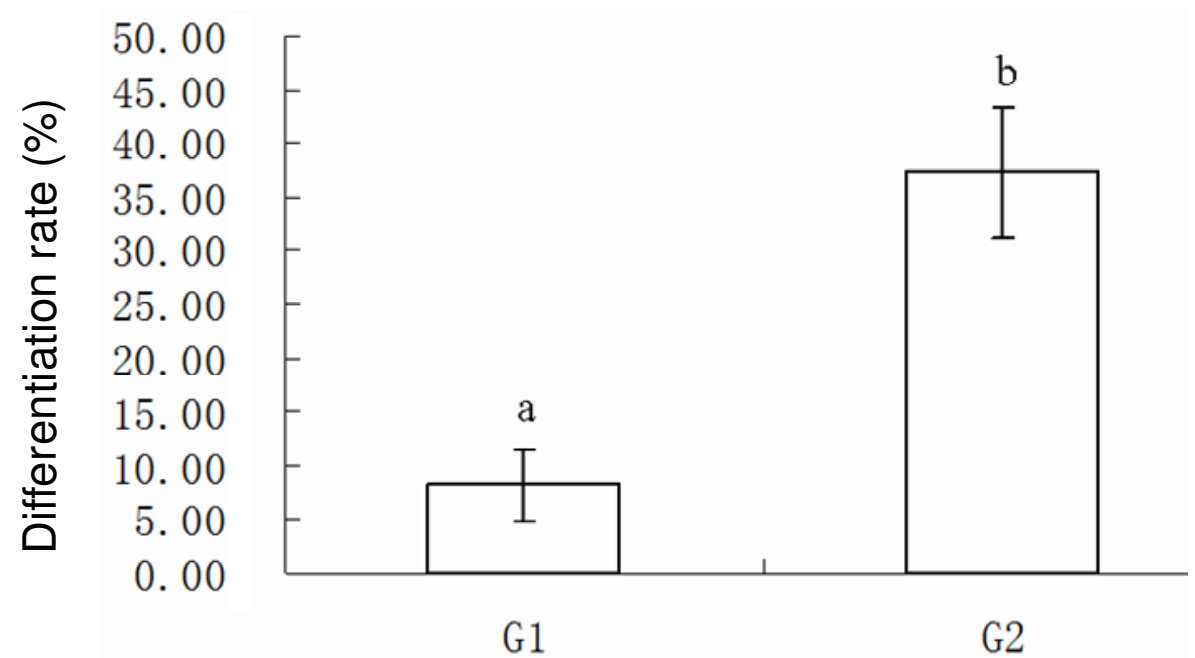

Figure 9. Comparation of differentiation rate.

Histone deacetylase (HDAC) inhibitors including $\mathrm{NaB}$, a short-chain fatty acid. It is reported that $\mathrm{NaB}$ could induce growth arrest, differentiation, and apoptosis in a number of cancer cells (Giuliano et al., 1999; Joseph et al., 2004). Previous study have showed that sodium butyrate could differentiate ESCs into hepatic progenitor cells (Rambhatla et al., 2003; Zhou et al., 2007), and depend on the concentration and exposure time (Ren et al., 2010). In addition, HGF has been shown to control the proliferation of fetal liver cells and support fetal hepatocytes during hepatogenesis (Uehara et al., 1995; Schmidt et al., 1995; Shelly et al., 1989). Meanwhile, glucocorticoids was reported to modulate the proliferation and function of adult hepatocytes (Kinoshita and Miyajima, 2002) and found to be involved in hepatic maturation. Consequently, HGF and Dex are core factor for the maturation of hepatocytes (Ong et al., 2006).

In our study, we used $3 \mathrm{M} \mathrm{NaB}$ as inducer for 7 days to differentiate ES cells into hepatic progenitor cells in the first phase, followed by the combination of HGF and Dex as inducer for 12 days to promote the maturation and proliferation and of hepatocytes in the second phase. The results from the morphology, gene expression, protein molecular markers and cell function of ES-D3 cells derived hepatocyte-like cells demonstrated that mES cells can be differentiated efficiently in vitro to functional hepatocytes under chemically defined conditions. About $37.27 \%$ of the mouse ES cells could be manipulated to differentiate into ALB-positive cells and the hepatic differentiation ratio in differentiated cells was much higher than that in spontaneously differentiation group. This simple, efficient and relatively economical method may be useful as an in vitro system for hepatocyte transplantation therapy and toxicity screening in drug discovery, while further studies are needed to elucidate the detailed molecular mechanism, and sort the desired cells to perform in vivo experiments to further test cell repopulation capacity.

\section{ACKNOWLEDGEMENTS}

This work was supported by grants from the National Natural Science Foundation (No. 30771554). The authors are grateful to $\mathrm{Dr}$ Yanli Zhang from our laboratory for critical reading and valuable suggestions.

\section{REFERENCES}

Chinzei R, Tanaka Y, Shimizu-Saito K, Hara Y, Kakinuma S, Watanabe M, Teramoto K, Arii S, Takase K, Sato C, Terada N, Teraoka H (2002). Embryoid-body cells derived from a mouse embryonic stem cell line show differentiation into functional hepatocytes. Hepatol., 36(1): 2229.

Drobinskaya I, Linn T, Saric T, Bretzel RG, Bohlen H, Hescheler J, Kolossov E (2008). Scalable selection of hepatocyte- and hepatocyte precursor-like cells from culture of differentiating transgenically modified murine embryonic stem cells. Stem Cells, 26(9): 2245-2256.

Gai H, Nguyen DM, Moon YJ, Aguila JR, Fink LM, Ward DC, Ma Y (2010). Generation of murine hepatic lineage cells from induced pluripotent stem cells. Differentiation, 79(3): 171-181.

Giuliano M, Lauricella M, Calvaruso G, Carabillò M, Emanuele S, Vento R, Tesoriere G (1999). The apoptotic effects and synergistic interaction of sodium butyrate and MG132 in human retinoblastoma Y79 cells. Cancer Res., 59(21): 5586-5595.

Gouon-Evans V, Boussemart L, Gadue P, Nierhoff D, Koehler Cl, Kubo A, Shafritz DA, Keller G (2006). BMP-4 is required for hepatic specification of mouse embryonic stem cell derived definitive endoderm. Nat. Biotechnol., 24(11): 1402-1411.

Hay DC, Zhao D, Ross A, Mandalam R, Lebkowski J, Cui W (2007). Direct differentiation of human embryonic stem cells to hepatocytelike cells exhibiting functional activities. Cloning Stem Cells, 9(1): 5162.

Joseph J, Mudduluru G, Antony S, Vashistha S, Ajitkumar P, Somasundaram K (2004). Expression profiling of sodium butyrate $(\mathrm{NaB})$-treated cells: identification of regulation of genes related to cytokine signaling and cancer metastasis by $\mathrm{NaB}$. Oncogene, 23(37): 6304-6315.

Kinoshita T, Miyajima A (2002). Cytokine regulation of liver development. Biochim. Biophys Acta., 1592(3): 303-312. 
Li W, Wang D, Qin J, Liu C, Liu C, Zhang Q, Zhang X, Yu X, Lahn BT, Mao FF, Xiang AP (2010). Generation of functional hepatocytes from mouse induced pluripotent stem cells. J. Cell Physiol., 222(3): 492501.

Liu H, Ye Z, Kim Y, Sharkis S, Jang YY (2010). Generation of endoderm-derived human induced pluripotent stem cells from primary hepatocytes. Hepatology, 51(5): 1810-1819.

Matsumoto K, Mizumoto H, Nakazawa K, ljima H, Funatsu K, Kajiwara T (2008). Hepatic differentiation of mouse embryonic stem cells in a three-dimensional culture system using polyurethane foam. J. Biosci. Bioeng., 105(4): 350-354.

Miyashita H, Suzuki A, Fukao K, Nakauchi H, Taniguchi H (2002). Evidence for hepatocyte differentiation from embryonic stem cells in vitro. Cell Transplant, 11(5): 429-434.

Mizumoto H, Aoki K, Nakazawa K, ljima H, Funatsu K, Kajiwara T (2008). Hepatic differentiation of embryonic stem cells in HF/organoid culture. Transplant Proc., 40(2): 611-613.

Ong SY, Dai H, Leong KW (2006). Hepatic differentiation potential of commercially available human mesenchymal stem cells. Tissue Eng., 12(12): 3477-3485.

Rambhatla L, Chiu CP, Kundu P, Peng Y, Carpenter MK (2003). Generation of hepatocyte-like cells from human embryonic stem cells. Cell Transplant, 12(1): 1-11

Ren M, Yan L, Shang CZ, Cao J, Lu LH, Min J, Cheng H (2010). Effects of sodium butyrate on the differentiation of pancreatic and hepatic progenitor cells from mouse embryonic stem cells. J Cell Biochem., 109(1): 236-244.

Schmidt C, Bladt F, Goedecke S, Brinkmann V, Zschiesche W, Sharpe M,Gherardi E, Birchmeier C (1995). Scatter factor/hepatocyte growth factor is essential for liver development. Nature, 373(6516): 699-702.

Shelly LL, Tynan W, Schmid W, Schutz G, Yeoh GC (1989). Hepatocyte differentiation in vitro: Initiation of tyrosine aminotransferase expression in cultured fetal rat hepatocytes. J. Cell Biol., 109(6): 3403-3410.

Shiraki N, Umeda K, Sakashita N, Takeya M, Kume K, Kume S (2008). Differentiation of mouse and human embryonic stem cells into hepatic lineages. Genes Cells, (7): 731-746.
Si-Tayeb K, Noto FK, Nagaoka M, Li J, Battle MA, Duris C, North PE, Dalton S, Duncan SA (2010). Highly efficient generation of human hepatocyte-like cells from induced pluripotent stem cells. Hepatology, 51(1): 297-305.

Soto-Gutiérrez A, Kobayashi N, Rivas-Carrillo JD, Navarro-Alvarez N, Zhao D, Okitsu T, Noguchi H, Basma H, Tabata Y, Chen Y, Tanaka K, Narushima M, Miki A, Ueda T, Jun HS, Yoon JW, Lebkowski J, Tanaka N, Fox IJ (2006). Reversal of mouse hepatic failure using an implanted liver-assist device containing ES cell-derived hepatocytes. Nat. Biotechnol., 24(11): 1412-1419.

Sullivan GJ, Hay DC, Park IH, Fletcher J, Hannoun Z, Payne CM, Dalgetty D, Black JR, Ross JA, Samuel K, Wang G, Daley GQ, Lee JH, Church GM, Forbes SJ, Iredale JP, Wilmut I (2010). Generation of functional human hepatic endoderm from human induced pluripotent stem cells. Hepatology, 51(1): 329-335.

Tanaka K, Soto-Gutierrez A, Navarro-Alvarez N, Rivas-Carrillo JD, Jun HS, Kobayashi N (2006). Functional hepatocyte culture and its application to cell therapies. Cell Transplant, 15(10): 855-864.

Teratani T, Yamamoto H, Aoyagi K, Sasaki H, Asari A, Quinn G, Sasaki $\mathrm{H}$, Terada M, Ochiya T (2005). Direct hepatic fate specification from mouse embryonic stem cells. Hepatology, 41(4): 836-846.

Uehara Y, Minowa O, Mori C, Shiota K, Kuno J, Noda T, Kitamura N (1995). Placental defect and embryonic lethality in mice lacking hepatocyte growth factor/scatter factor. Nature, 373(6516): 702-705.

Zhou QJ, Xiang LX, Shao JZ, Hu RZ, Lu YL, Yao H, Dai LC (2007). In vitro differentiation of hepatic progenitor cells from mouse embryonic stem cells induced by sodium butyrate. J Cell Biochem., 100(1): 2942. 